\title{
Gambaran Pelaksanaan Identifikasi Pasien Sebelum Melakukan Tindakan Keperawatan di RSUD Wates
}

\author{
Fatma Siti Fatimah ${ }^{1}$, Lilis Sulistiarini ${ }^{2}$, Fatimah $^{3}$, \\ ${ }^{1}$ Administrasi Rumah Sakit, Universitas Alma Ata \\ ${ }^{2}$ IImu Keperawatan, Universitas Alma Ata \\ ${ }^{3}$ kebidanan, Universitas Alma Ata \\ EMail: fatmasitifatimah@gmail.com \\ Jalan Brawijaya No. 99 Yogyakarta
}

\section{Abstrak}

Penelitian ini mengungkapkan gambaran pelaksanaan identifikasi pasien sebelum melakukan tindakan keperawatan di RSUD Wates. Kesalahan identifikasi pasien sering terjadi di tahapan diagnosis dan pengobatan sehingga diperlukan ketepatan identifikasi pasien. Penelitian ini bertujuan untuk mengetahui gambaran identifikasi pasien sebelum melakukan tindakan keperawatan di RSUD Wates.

Metode kuantitatif yang menghasilkan data deskriptif dengan cara observasi sehingga dapat menggambarkan pelaksanaan identifikasi pasien di RSUD Wates. Instrumen yang digunakan yaitu lembar observasi. Teknik pengambilan sampel menggunakan random sampling dengan jumlah sampel 135 respoden perawat.

Hasil penelitian ini menunjukkan karakteristik responden yang berusia 17-26 tahun $17 \%, 26-35$ tahun 57,8 \%, 36-45 tahun $23 \%$ dan 46-55 tahun 2,2\%. Jenis kelamin laki-laki 22,2 \% dan perempuan 77,8\%. Pendidikan DIII Keperawatan 91,1\%, D IV $5,2 \%$ dan S1 3,7 \%. Masa kerja 1-10 tahun 77,8 \%, 11-20 tahun 18,5\%, masa kerja 21-30 tahun 3,7 \%. Status kepegawaian non PNS 69,9\% dan PNS 30,4 \%.

Kesimpulan hasil penelitian ini Dilakukan identifikasi $71,9 \%$ dan tidak dilakukan identifikasi 28,1 \%. Pelaksanaan identifikasi sebelum transfusi darah $100 \%$, sebelum tindakan $75,5 \%$, sebelum pengambilan darah $75 \%$ dan sebelum pemberian obat $64,1 \%$.

Kata Kunci: Identifikasi Pasien, Keselamatan Pasien

\section{Description of The Implementation Of Patient Identification Before Taking Nursing Action In RSUD Wates}

\section{Abstract}

This study describe the implementation of patient's identification before performing nursing action in RSUD Wates. Patient identification errors often occur in the stages of diagnosis and treatment so that accurate patient identification is necessary. To describe the iplementation of patient's ientification before performing nursing action in RSUD Wates. This research used quantitative method that results in descriptive data by means of observation that is able to illustrate the implementation of patient identification in RSUD Wates. used instrument is an observation sheet. Sampling technique is performed by random sampling with number of sample 135 nurse respondents. Result this research respondents varies by age with number of respondents aged 17-26 years old as 17\%, 26-35 y-o as 57,8\%, 36-45 y-o as $23 \%$ and 46-55 y-o as 2,2\%. Male gender 22,2 \% and female 77,8\%. Respondents with DIII Nursing Educational background are 91,1\%, D IV are 5,2\% and bachelor degree are 2,7 \%. Length of working 1-10 years $77,8 \%, 11-20$ years 18,5\%, 21-30 years 3,7\%. Employment status: non goverment employees $69,9 \%$ and goverment employees 30,4\%.Conclusion: Identification is performed by $71,9 \%$ nurses and is not performed by 28,1\% nurses. Implementation of identification before blood transfusion $100 \%$, before nursing action 75,5\%, before blood collection $75 \%$ and before treatment $64,1 \%$.

Keywords: Patient Identification, Patient Safety

Received: 25/12/2017; published: 28/05/2018

\section{PENDAHULUAN}

Keamanan pasien di rumah sakit dimulai dari ketepatan identifikasi pasien. Kesalahan identifikasi diawal pelayanan akan berdampak pada kesalahan pelayanan tahap berikutnya.
Rumah Sakit harus menjamin proses identifikasi pasien ini berjalan dengan benar sejak pertama kali pasien didaftarkan (1). Kesalahan dalam mengidentifikasi pasien dapat terjadi dihampir semua tahapan diagnosis dan 
pengobatan. Hal ini dapat terjadi pada pasien dalam keadaan terbius, mengalami disorientasi, tidak sadar, pindah ruang, adanya kelainan sensori dan lain sebagainya (2).

Berdasarkan

sasaran

keselamatan pasien yang pertama pada

Standar Akreditasi Rumah Sakit tahun 2012 menyebutkan bahwa identifikasi pasien penting untuk mengidentifikasi pasien yang akan mendapatkan pelayanan atau pengobatan agar tidak terjadi kekeliruan. Dalam mengidentifikasi pasien menggunakan nama dan tanggal lahir pasien bukan menggunakan nomor kamarnya saja.

Proses identifikasi dimulai dari pasien masuk rumah sakit dan akan terus dikonfirmasi pada saat sebelum pemberian obat, pemberian darah atau produk darah, sebelum mengambil darah atau spesimen lain untuk pemeriksaan, dan juga sebelum melakukan pengobatan atau prosedur tindakan (3). Data laporan keselamatan pasien Pemerintah Australia bagian selatan terdapat 5 jenis kesalahan identifikasi pasien yang sering terjadi pada tahun 2014-2015 yaitu salah mengidentifikasi pasien 273 kasus, kesalahan label pada spesimen 272 kasus, salah pasien 211 kasus, salah status rekam medis 59 kasus dan kesalahan hasil pemeriksaan sebanyak 28 kasus (4).

Data tentang laporan Insiden Keselamatan Pasien yang disitasi dari Yudhawati \& Ekorini Listiowati salah satu penyebab KTD adalah salah identifikasi yang dilakukan oleh petugas kesehatan RS. penelitian sebelumnya menyebutkan resiko plebitis pada pasien $(5,6)$. Data insiden keselamatan pasien tahun 2012 melaporkan analisis penyebab terjadinya insiden $46 \%$ berkaitan dengan salah identifikasi, 36 \% dikarenakan karena komunikasi yang tidak efektif sehingga terjadi medication error, $18 \%$ dikarenakan prosedur tidak dijalankan (7).

Data Tim Mutu RSUD Wates terdapat insiden keselamatan pasien di RSUD Wates dari bulan Januari sampai dengan Maret 2017 terdapat 31 laporan kasus insiden. Dua belas diantaranya menyangkut identifikasi pasien yaitu 7 laporan pasien tidak terpasang gelang, 4 laporan kesalahan gelang. Perlunya mengimplementasikan patient safety untuk meningkatkan mutu kualitas rumah sakit (8).

Tujuan Umum penelitian ini untuk mengetahui gambaran pelaksanaan identifikasi pasien sebelum melakukan tindakan keperawatan di RSUD Wates. Tujuan Khusus untuk mengetahui karakteristik responden atau perawat yang meliputi usia, jenis kelamin, pendidikan, masa kerja dan status kepegawaian di RSUD Wates serta untuk mengetahui persentase pelaksanaan identifikasi pasien sebelum pemberian obat, pengambilan sampel darah, sebelum tindakan dan sebelum transfusi darah di RSUD Wates.

\section{BAHAN DAN METODE}

Rancangan penelitian ini merupakan penelitian deskriptif. Penelitian deskriptif adalah penelitian yang dilakukan untuk mengetahui nilai variabel mandiri, baik satu variabel atau lebih tanpa membuat perbandingan, atau penghubungan dengan variabel lain (9),(10). Metode analisa data adalah analisis univariat yaitu dengan menganalisis variabel secara deskriptif dengan melihat frekuensi dari setiap variabel dan dianalisa secara deskriptif Fatimah, FS. Sulistiarini, L. Fatimah. 2018. Indonesian Journal of Hospital Administration 
dalam bentuk frekuensi dan persentase (11). Penelitian ini dilakukan di ruang rawat inap RSUD Wates Kulon Progo. Populasi penelitian ini adalah perawat pada ruang rawat inap sejumlah 206 orang perawat. Metode pengambilan sampel dengan teknik pengambilan secara acak (symple random sampling) dengan memperhatikan kriteria inklusi dan eksklusi. Kriteria inklusi dalam penelitian ini perawat pada ruang rawat inap RSUD Wates yang bersedia menjadi responden, perawat yang akan melakukan tindakan keperawatan berupa pemberian obat, pemberian transfusi darah dan produk darah, pengambilan sampel darah atau spesimen sputum, urine atau feces, dan perawat pendidikan minimal D III Keperawatan dengan masa kerja minimal 1 tahun. Sedangkan kriteria eksklusi yaitu perawat dengan masa kerja kurang dari 1 tahun serta perawat yang tidak bersedia menjadi responden. Variabel dalam penelitian ini yaitu pelaksanaan identifikasi pasien sebelum melakukan tindakan keperawatan di RSUD Wates. Besar sampel dihitung menggunakan rumus Slovin sejumlah 135 orang perawat (9). Instrumen penelitian menggunakan lembar observasi (check list) yang disusun berdasarkan SPO Identifikasi Pasien di RSUD Wates.

\section{HASIL DAN PEMBAHASAN \\ Hasil \\ Karakteristik Responden}

Responden pada penelitian ini merupakan perawat di ruang rawat inap RSUD Wates. Secara lengkap karakteristik responden meliputi usia, jenis kelamin, pendidikan, masa kerja dan status kepegawaian yang akan disajikan dalam Tabel 1 berikut:

Fatimah, FS. Sulistiarini, L. Fatimah. 2018. Indonesian Journal of Hospital Administration
Tabel 1 Distribusi Frekuensi Karakteristik Perawat di Ruang Rawat Inap RSUD Wates

\begin{tabular}{|c|c|c|}
\hline $\begin{array}{l}\text { Karakteristik } \\
\text { Responden }\end{array}$ & Frekuensi & $\begin{array}{l}\text { Persentase } \\
(\%)\end{array}$ \\
\hline \multicolumn{3}{|l|}{ Usia } \\
\hline 17-25 tahun & 23 & 17,0 \\
\hline 26-35 tahun & 78 & 57,8 \\
\hline 36-45 tahun & 31 & 23,0 \\
\hline 46-55 tahun & 3 & 2,2 \\
\hline \multicolumn{3}{|l|}{ Jenis Kelamin } \\
\hline Laki-laki & 30 & 22,2 \\
\hline Perempuan & 105 & 77,8 \\
\hline \multicolumn{3}{|l|}{ Pendidikan } \\
\hline $\begin{array}{l}\text { DIII } \\
\text { Keperawatan }\end{array}$ & 123 & 91,1 \\
\hline $\begin{array}{l}\text { DIV } \\
\text { Keperawatan }\end{array}$ & 7 & 5,2 \\
\hline $\begin{array}{l}\text { S1 } \\
\text { Keperawatan }\end{array}$ & 5 & 3,7 \\
\hline \multicolumn{3}{|l|}{ Masa Kerja } \\
\hline 1-10 tahun & 105 & 77,8 \\
\hline 11-20 tahun & 25 & 18,5 \\
\hline 21-30 tahun & 5 & 3,7 \\
\hline \multicolumn{3}{|l|}{ Status } \\
\hline \multicolumn{3}{|l|}{ Kepegawaian } \\
\hline PNS & 41 & 30,4 \\
\hline Non PNS & 94 & 69,6 \\
\hline
\end{tabular}

Sumber : Data Primer, 2017

Tabel 1 menunjukkan bahwa sebagian besar responden berusia 2635 tahun sebanyak 78 perawat $(57,8 \%)$, jenis kelamin perempuan sebanyak 105 perawat $(77,8 \%)$, tingkat pendidikan D III Keperawatan sebanyak 123 perawat $(91,1 \%)$, masa kerja 1-10 tahun sebanyak 105 perawat $(77,8 \%)$ dan status kepagawaian Non PNS yaitu 93 perawat $(69,6 \%)$.

\section{Data Demografi Responden}

Usia

Karakteristik responden berdasarkan usia didominasi oleh usia 26-35 tahun sejumlah 57,8\%. Hal ini sesuai dengan penelitian Fatimah di Rumah Sakit PKU Muhammadiyah Yogyakarta Unit II yang didapatkan karakteristik responden perawat terbanyak berumur 25-35 tahun sebesar $56,2 \%$ (12). Seiring dengan bertambahnya usia seseorang, akan terjadi perubahan dari segi fisik maupun psikologi. Pertambahan usia bisa berpengaruh terhadap daya tangkap 
dan pola pikir seseorang termasuk pengetahuan dan kepatuhan. Akan tetapi hal tersebut tidak terlepas dari faktor lain juga yang mempengaruhi (12),(13).

\section{Jenis Kelamin}

Karakteristik responden berdasarkan jenis kelamin didominasi oleh jenis kelamin perempuan yaitu sebanyak 105 responden $(77,8 \%)$ karena jumlah perawat di RSUD Wates mayoritas perempuan. Hal ini diperkuat dengan penelitian Fatimah di Rumah Sakit PKU Muhammadiyah Yogyakarta Unit II yang menyebutkan bahwa 90,7\% responden berjenis kelamin perempuan (12). Dilanjutkan oleh penelitian yang dilakukan di klinik pratama kasihan Bantul yang menunjukkan hasil serupa (13).

\section{Pendidikan}

Karakteristik

responden

berdasarkan tingkat pendidikan didominasi oleh D III Keperawatan (91,1 \%), D IV Keperawatan 5,2 \% dan S1 Keperawatan 3,7 \%. Banyaknya perawat berpendidikan D III Keperawatan dalam penelitian ini dipengaruhi oleh mayoritas pendidikan perawat di RSUD Wates adalah D III Keperawatan.

Perawat berpendidikan D III Keperawatan tersebar dalam semua ruang rawat inap di RSUD Wates sedangkan perawat berpendidikan D IV Keperawatan dan S1 Keperawatan masih berjumlah sedikit. Hal ini sesuai dengan penelitian Anggraini di RSUP Ratatotok Buyat yang menyatakan bahwa 93,8 \% perawat berpendidikan D III Keperawatan dan yang berpendidikan S1 hanya $6,3 \%(14)$.

\section{Masa Kerja}

Karakteristik responden berdasarkan masa kerja didominasi oleh masa kerja 1-10 tahun yaitu sejumlah 105 (77,8\%). Sedangkan pada penelitian Ariyati di RSJ Prof. Dr. Soerojo Magelang mayoritas responden masa kerja lebih dari 10 tahun 53,8 \% dan masa kerja 2-10 tahun 46,2 \% (15).

\section{Status Kepegawaian}

Karakteristik

responden berdasarkan status kepegawaian didominasi oleh perawat Non PNS yaitu sejumlah 94 responden (69,6 \%). Hal ini sebanding dengan penelitian Yuningsih di RSD Balung yaitu mayoritas reponden perawat berstatus Non PNS $63,3 \%$ dan yang PNS 36,7 \% (16).

Tabel 2 Gambaran Persentase Pelaksanaan Identifikasi Pasien Sebelum Melakukan Tindakan Keperawatan di RSUD Wates

\begin{tabular}{lcc}
\hline Keterangan & Frekuensi & Persentase \\
\hline Tidak & 38 & 28,1 \\
Dilakukan & & \\
\hline Dilakukan & 97 & 71,9 \\
\hline Total & 135 & 100 \\
\hline
\end{tabular}
Sumber : Data Primer, 2017

Berdasarkan Tabel 2 dapat diketahui bahwa pelaksanaan identifikasi pasien sebelum melakukan tindakan keperawatan yaitu 71,9 \%. Sedangkan yang tidak dilakukan identifikasi yaitu 28,1 \%. Hal ini sebanding dengan penelitian yang dilakukan oleh Umaternate di RSUP Prof. Dr. RD Kandou Manado yang didapatkan 64,5\% perawat melakukan identifikasi pasien dengan benar dan $35,5 \%$ perawat melakukan identifikasi pasien secara tidak benar (17). 
Tabel 3 Gambaran Rincian Pelaksanaan Identifikasi Pasien

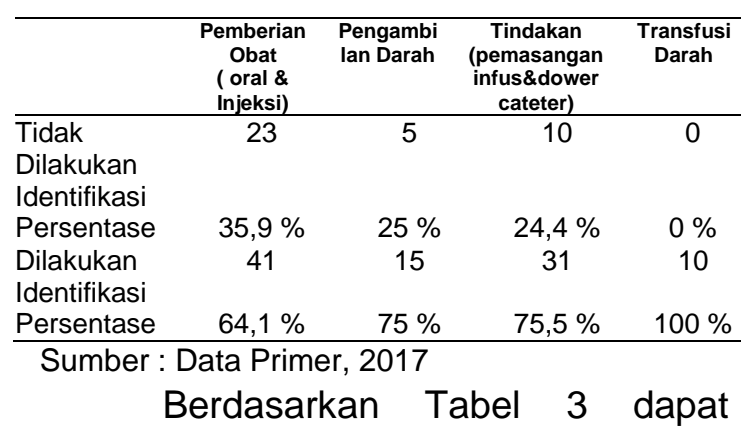

diketahui bahwa identifikasi tertinggi dilakukan sebelum pemberian transfusi darah yaitu 100 \%. Identifikasi pasien sebelum melakukan tindakan sebesar 75,5\%. Identifikasi sebelum pengambilan darah sebesar $75 \%$. Identifikasi pasien paling sedikit dilakukan pada saat pemberian terapi yaitu $64,1 \%$.

Dalam penelitian ini masih terdapat $28,1 \%$ tidak dilakukan identifikasi pasien dan terbagi dalam identifikasi sebelum pemberian obat, pengambilan darah, sebelum tindakan keperawatan dan sebelum transfusi. Dalam identifikasi pasien sebelum pemberian obat terdapat 35,9\% tidak dilakukan identifikasi. Identifikasi pasien sebelum pemberian obat mutlak dilakukan untuk menghindari terjadinya kesalahan pasien dimana dalam pemberian obat seharusnya tidak boleh terjadi kesalahan.

Hasil penelitian menunjukkan identifikasi pasien bisa dilaksanakan salah satunya dengan penerapan prinsip benar (benar pasien, benar obat dII) oleh petugas kesehatan untuk mengurangi resika IKP yang merugikan pasien $(12,18)$. Sebelum pengambilan darah terdapat $25 \%$ tidak dilakukan identifikasi pasien. Identifikasi sebelum pemberian darah penting dilakukan untuk menghindari kesalahan hasil pemeriksaan yang dapat menyebabkan salah diagnostik.

Identifikasi sebelum melakukan tindakan terdapat 24,4 \% tidak dilakukan. Tindakan yang dimaksud dalam penelitian ini yaitu tindakan pemasangan infus dan dower cateter. Dalam memberikan pelayanan keperawatan kepada pasien perawat melakukan tindakan keperawatan yang banyak dan menimbulkan resiko salah yang begitu besar sehingga pelaksanaan identifikasi pasien sebelum melakukan tindakan harus dilakukan.

Identifikasi pasien sebelum transfusi sudah $100 \%$ dilakukan. Hal ini dapat terjadi karena sudah terdapat formulir pemantauan transfusi sehingga perawat memberikan transfusi sudah berpedoman kepada formulir tersebut. Kesalahan transfusi mempunyai resiko yang fatal sehingga sebelum transfusi perawat $100 \%$ melakukan identifikasi pasien.

Mengingat tingginya angka yang tidak dilakukan identifikasi pasien terutama saat pemberian obat, pengambilan darah dan sebelum tindakan perlu dilakukan audit sehingga dapat diketahui faktor penghambat yang menyebabkan perawat tidak patuh terhadap pelaksanaan identifikasi pasien agar dapat ditindaklanjuti.

Monitoring dan evaluasi penerapan SPO secara berkala oleh komite keperawatan juga perlu dilakukan untuk meningkatkan kepatuhan pelaksanaan identifikasi pasien sehingga dapat menurunkan angka insiden keselamatan pasien.

\section{SIMPULAN DAN SARAN}

\section{Simpulan}

Hasil penelitian menunjukkan identifikasi

dilakukan sebesar 71,9 \% dan yang Fatimah, FS. Sulistiarini, L. Fatimah. 2018. Indonesian Journal of Hospital Administration 
tidak dilakukan sebesar 28,1 \%. Pelaksanaan identifikasi paling banyak dilakukan sebelum memberikan transfusi darah yaitu $100 \%$. Identifikasi sebelum melakukan tindakan sebanyak $75,5 \%$. Sebelum pengambilan darah dilakukan identifikasi sebesar $75 \%$ dan sebelum pemberian obat dilakukan identifikasi sebesar 64,1\%. Karakteristik responden berdasarkan usia mayoritas berusia 26-35 tahun yaitu 57,8 \%. Mayoritas jenis kelamin yaitu perempuan sebanyak $77,8 \%$. Mayoritas responden berpendidikan D III Keperawatan sebesar 91,1 \%. Masa kerja responden mayoritas 1-10 tahun yaitu $77,8 \%$ dan status kepegawaian mayoritas Non PNS sebesar 69,9\%.

\section{Saran}

Rumah sakit perlu menggiatkan lagi sosialisasi tentang identifikasi pasien kepada seluruh petugas kesehatan, dilakukan monitoring secara rutin dan evaluasi terhadap pelaksanaan identifikasi pasien sebelum melakukan tindakan keperawatan, pemberian obat, pemberian transfusi darah, pengambilan sampel darah di setiap ruangan sehingga dapat meningkatkan mutu Rumah Sakit. Perlu dilakukan penerapan standar kompetensi pada proses kredensial bagi pegawai dalam melaksanakan sasaran keselamatan pasien khususnya pelaksanaan identifikasi pasien. Perawat perlu mengikuti upgrade knowledge tentang sasaran keselamatan pasien khususnya identifikasi pasien sehingga dapat meningkatkan mutu dan pelayanan Rumah Sakit.

\section{DAFTAR PUSTAKA}

1. World health organization. Patient Identification. Patient Safety Solution [Internet]. 2007. Available Fatimah, FS. Sulistiarini, L. Fatimah. 2018. Indonesian Journal of Hospital Administration from:

http://www.who.int/patientsafety/sol utions/patientsafety/PS-

Solution2.pdf.

2. Komisi Akreditasi Rumah Sakit. Instrumen Akreditasi Rumah Sakit Standar Akreditasi versi 2012. Jakarta: KARS; 2012.

3. Peraturan Menteri Kesehatan Republik Indonesia. No 1691/MENKES/PER/VIII/2011

tentang Keselamatan Pasien [Internet]. Jakarta; 2011. Available from: http://bprs.kemkes.go.id

4. South Australian Patient Safety Report 2013-2014. Govermenth South Aust SA Heal [Internet]. 2014; Available from: http://www.sahealth.sa.gov.au/wps/ wcm/connect/7209378046aaedec99 a4fb2e504170d4/1_Patient+Safety+ Report

5. Putri IR. Pengaruh Lama Pemasangan Infus dengan Kejadian Flebitis pada Pasien Rawat Inap di Bangsal Penyakit Dalam dan Syaraf Rumah Sakit Nur Hidayah Bantul. J Ners dan Kebidanan Indones. 2016;4(2):904.

6. Rizky W, Supriyatiningsih S. Surveillance Kejadian Phlebitis pada Pemasangan Kateter Intravena pada Pasien Rawat Inap di Rumah Sakit Ar. Bunda Prabumulih. J Ners dan Kebidanan Indones. 2016;2(1):42-9.

7. Yudhawati DD, Listiowati $E$. Evaluasi Penerapan Identifikasi Pasien di Bangsal Rawat Inap RSI Siti Aisyah Madiun. JMMR (Jurnal Medicoeticolegal dan Manaj Rumah Sakit). 2016;4(2).

8. Sumarni. Analisis Implementasi 
Patient Safety Terkait Peningkatan Mutu Pelayanan Kesehatan di Rumah Sakit. J Ners dan Kebidanan Indones. 2017;5(2):919.

9. Nasir A, Muhith A, Ideputri ME. Buku Ajar Metodologi Penelitian Kesehatan. Yogyakarta: Nuha Medika; 2011.

10. Hidayat AAA. Metode penelitian keperawatan dan teknik analisis data. 1st ed. Jakarta: Medika Salemba; 2007.

11. Dahlan MS. Statistik untuk kedokteran dan kesehatan. 5th ed. Aklia S, editor. Jakarta: Salemba Medika; 2011.

12. Fatimah FS. Gambaran Penerapan Prinsip Benar Pemberian Obat di Rumah Sakit PKU Muhammadiyah Yogyakarta Unit II. J Ners dan Kebidanan Indones. 2016;4(2):79.

13. Fatimah F, Kaidati M, BI Yulitasari -. Relationship Characteristics of Respondents between Implementation of Patient Safety at Clinic Pratama Kasihan Bantul Yogyakarta $2017 . \quad$ ICHAA. 2018;159.

14. Bantu A, Mulyadi N, Bidjuni $H$. Hubungan Pengetahuan Perawat
Dengan Penerapan Identify Patient Correcly Di Rsup Ratatotok Buyat Kabupaten Minahasa Tenggara. J Keperawatan. 2(2).

15. Ariyati $\mathrm{T}$, Apriyatmoko $\mathrm{R}$, Pranoto H. Hubungan Karakteristik Perawat Dengan Kepatuhan Penerapan Prosedur Keselamatan Pasien Di Instalasi Rawat Inap II RSJ Prof. dr. Soerojo Magelang. 2016;

16. Yuningsih DYA. Hubungan Status Kepegawaian Perawat dengan Perilaku Caring Perawat Pada Pasien di Ruang Rawat Inap Kelas 3 RSD Balung. 2015;

17. Lombogia A, Julia R, Karundeng $M$. Hubungan Perilaku Dengan Kemampuan Perawat Dalam Melaksanakan Keselamatan Pasien (Patient Safety) Di Ruang Akut Instalasi Gawat Darurat Rsup Prof. Dr. RD Kandou Manado. J KEPERAWATAN. 2016;4(2).

18. Anggraini AN, Fatimah FS. Evaluasi Penerapan Patient Safety dalam Pemberian Obat di Wilayah Kerja Puskesmas Kasihan II Kabupaten Bantul Yogyakarta. J Ners dan Kebidanan Indones. 2015;3(3):1628. 